DOI: https://doi.org/10.47405/mjssh.v6i6.815

\begin{tabular}{|c|c|}
\hline$x_{10}$ & Malaysian Journal of Social Sciences and Humanities (MJSSH) \\
\hline $\begin{array}{l}\text { Malaysian Journal of } \\
\text { Solas iscieches and }\end{array}$ & Volume 6, Issue 6, June 2021 \\
\hline (MJ-sSH) & e-ISSN : 2504-8562 \\
\hline & $\begin{array}{l}\text { Journal home page: } \\
\text { www.msocialsciences.com }\end{array}$ \\
\hline
\end{tabular}

\title{
Aspek Kebajikan Menjadi Keutamaan Buat Anggota Polis di Malaysia
}

Fatinfarazira Mohd Aziz ${ }^{\mathbf{1}}$, Mohamad Fauzi Abdul Latib ${ }^{\mathbf{1}}$

${ }^{1}$ Fakulti Sains Sosial Gunaan, Universiti Sultan Zainal Abidin (UniSZA)

Correspondence: Fatinfarazira Binti Mohd Aziz (fatinfarazira@gmail.com)

\begin{abstract}
Abstrak
Seperti yang diketahui umum, anggota polis berdepan dengan pelbagai dugaan serta terdedah kepada bahaya semasa menjalankan tugasan. Anggota polis bertindak balas terhadap pelbagai aktiviti jenayah semasa menjalankan tugas bagi menjaga keselamatan dalam negara. Oleh itu, kebajikan mereka perlu dijaga supaya dapat memastikan kepentingan umum lebih terjamin. Objektif utama penyelidikan ini adalah untuk mengenal pasti cadangan penambahbaikan dalam aspek kebajikan terhadap anggota polis dalam menangani isu kebajikan. Penyelidikan ini merupakan penyelidikan kualitatif yang menggunakan pendekatan kajian kes melalui kaedah temu bual mendalam. Ibu Pejabat Polis Kontinjen Negeri Terengganu telah dipilih sebagai lokasi kajian dengan melibatkan 11 orang responden. Pemilihan sampel dilakukan secara bertujuan dan data yang diperoleh di analisis secara tematik. Hasil kajian mendapati terdapat tiga cadangan utama bagi penambahbaikan dalam aspek kebajikan untuk anggota polis iaitu menambahbaikkan struktur dan keselamatan perumahan, memudahkan urusan kelulusan cuti anggota dan menyediakan kursus kepada penyelia agar dapat meningkatkan produktiviti kerja sekaligus dapat memberi kesan positif terhadap prestasi organisasi serta melengkapkan kefungsian sosial anggota polis.
\end{abstract}

Kata Kunci: kebajikan, polis, cadangan, Malaysia

\section{Welfare Aspects Become a Priority for The Police Officers in Malaysia}

\begin{abstract}
As known, police officers will face various allegations and exposed to danger while on duty. Police personnel will respond directly to the various criminal activities until the end. Then, they can carry out their duties to maintain security for the country. Therefore, their welfare needs to be taking care, in order to ensure that the public interest is more secure. Objective for this research is to identify the suggestions for improvement in the welfare aspect of police personnel for addressing welfare issues. This research had been used a qualitative method with a case study approach through in-depth interviews. Then, the Terengganu State Contingent Police Headquarters was selected as the study area involving 11 respondents. The selection of the sample was done purpose sample and the data obtained were analyzed thematically. Finding for this research, it shows that there are three main suggestions for improvement in the aspect of welfare for police personnel. So, they hope that the structure and security of housing will fix as soon as possible and facilitating the approval of member leave and also providing courses for supervisors in order to increase work productivity for the positive impact on organizational performance and recovered the social functionality.
\end{abstract}

Keywords: welfare, police, suggestion, Malaysia 


\section{Pengenalan}

Menurut Yusoff (2016), perlakuan jenayah tanpa sempadan menjadikan tugas polis semakin bertambah akibat daripada kepelbagaian tektik baru perlakuan jenayah dalam kalangan masyarakat. Hal ini kerana, keadaan masyarakat yang kurang berpengetahuan, masalah jenayah yang semakin kritikal dan desakan daripada peluasan globalisasi pada masa kini yang agak membimbangkan (Metcalfe \& Dick, 2000). Mohamed Sazif dan Venugopal (2011) berkata, Polis Diraja Malaysia (PDRM) merupakan badan penguatkuasaan utama negara dan tanggungjawab polis adalah melindungi serta menjaga ketenteraman awam. Seperti sedia maklum, polis dan masyarakat berpisah tiada dan polis merupakan penjawat awam yang sentiasa berhubung dengan masyarakat. Oleh itu, polis sering mengalami gangguan emosi dan keseimbangan kehidupan yang tidak konsisten (Patterson, 2009; Slate, 2007). Di Malaysia, kita sebagai rakyat masih boleh hidup dengan aman dan damai kerana dengan adanya penguatkuasa seperti polis. Walaupun tidak bebas dari jenayah, namun kita perlu bersyukur dilahirkan sebagai rakyat Malaysia dan masih lagi bebas melakukan aktiviti harian.

Kita juga tidak mengalami nasib yang sama seperti negara-negara jiran yang sentiasa menghadapi krisis dan ancaman seperti pengeboman. Hal ini kerana, kita mempunyai penguatkuasa yang menjaga keselamatan negara serta memelihara ketenteraman awam terutamanya polis dan tentera. Kedua-dua pasukan tersebut merupakan pasukan keselamatan negara yang bertanggungjawab menjaga keselamatan negara daripada ancaman luar dan dalam. Seperti yang diketahui umum, anggota polis berdepan dengan pelbagai dugaan serta terdedah kepada bahaya semasa menjalankan tugas. Anggota polis bertindak balas terhadap pelbagai aktiviti jenayah serta menjalankan tugas bagi menjaga keselamatan dalam negara (Azman, 2020). Oleh itu, kebajikan mereka perlu dijaga supaya dapat memastikan kepentingan umum juga terjamin (Johari Yap, 2019).

Kebajikan akan dilakukan sebaik mungkin dalam menjaga hubungan terhadap Allah dan sesama manusia. Kebajikan menurut Mohamad Khadafi (2015) ialah perbuatan baik yang dilakukan terhadap sesama manusia seperti yang dituntut oleh syariat Islam. Kebajikan juga merujuk kepada nilai kebaikan dan bekerjasama terhadap orang yang dapat dilihat melalui tindakan dan berperanan sebagai pencetus kesepakatan dan penyatuan antara sesama manusia. Abdullah (2015) merumuskan tentang konsep kebajikan sebagai satu terma kebajikan yang dinyatakan dalam Al-Quran yang menggambarkan luasnya kebaikan termasuklah ketaatan kepada Allah sama ada dalam aqidah dan amal perbuatan serta mereka yang melakukan kebaikan merupakan orang yang benar dan bertaqwa.

Oleh yang demikian, kebajikan merupakan salah satu perkara penting yang tidak boleh diabaikan kerana ia adalah pemacu dalam meningkatkan kesan yang positif terhadap seseorang individu tersebut. Namun begitu, menurut Moradi et al., (2012); Graham, (2012); Ghoreishi et al., (2014); Mohd Bokti dan Abu Talib, (2010); Jusoh dan Mhamat Nasudin, (2013), keperluan individu berkait rapat dengan persekitaran kerja yang baik dan ia berhubung dengan keperluan yang mempengaruhi kesan terhadap organisasi. Malah, jika diabaikan gaya hidup sihat dalam aspek kebajikan ia akan mengundang masalah lain seperti tekanan mental, kemurungan dan fizikal. Selain itu, ia juga akan memberikan kesan negatif kepada hubungan dengan ahli keluarga dan rakan sekerja (Violanti et al., 2013; Yun et al., 2013).

Antara contoh kebajikan yang diperlukan oleh anggota polis ialah kebajikan dari segi perumahan. Johari Yap (2019) melaporkan, sebuah perumahan anggota polis di Selangor mempunyai beberapa lubang besar selebar kira-kira setengah meter di lorong kawasan perumahan tersebut. Hal ini sangat menyedihkan dan amat membahayakan keselamatan penghuni di perumahan anggota polis terutama pada waktu malam dan ditambah pula dengan lampu jalan yang rosak. Selain itu, tinjauan juga telah dilakukan pada tahun 2016 oleh sebuah akhbar tempatan di dua lagi perumahan anggota polis iaitu di Sentul dan Setiawangsa juga amat menyedihkan apabila keadaan bangunan di perumahan tersebut sudah luntur catnya dan jeriji besi di balkoni juga berkarat (Johari, 2019). Sangat menyedihkan lagi apabila lif juga sudah sekian lama tidak berfungsi. Keadaan bertambah menyedihkan kerana ada golongan wanita yang hamil dan anggota polis yang sudah berusia tinggal di kediaman tersebut. Oleh 
itu, segala kerosakan infrastruktur di semua perumahan polis di seluruh negara perlu diambil tindakan segera agar anggota polis dapat hidup dengan selesa. Dengan keselesaan hidup tersebut, anggota polis dapat mencapai tahap kepuasan kerja yang maksimum. Oleh itu berdasarkan kekangan yang diperoleh melalui bacaan pengkaji, kajian ini memfokuskan tentang aspek kebajikan anggota PDRM kontinjen Terengganu. Faktor kebajikan akan terus menjadi keutamaan dalam memainkan peranan penting dalam meningkatkan motivasi kerja anggota polis. Sebagai balasan, pekerja yang berpuas hati dengan kemudahan kebajikan yang disediakan oleh majikan, akan dapat membantu meningkatkan produktiviti kerja sekaligus dapat memberi kesan positif terhadap prestasi organisasi.

\section{Polis}

Pada tahun 1948, Persekutuan Tanah Melayu Telah ditubuhkan. Oleh itu, di bawah Pesuruhjaya Polis telah terdirinya pasukan Polis Persekutuan Tanah Melayu dan pada masa kini nama pasukan polis telah ditukar kepada Polis Diraja Malaysia (PDRM) yang juga tertakluk di bawah Pesuruhjaya Polis (Nhan Dan, 2015). Seperti yang sedia maklum, terdapat pelbagai perkhidmatan yang disediakan oleh pihak polis yang melibatkan risiko kehilangan nyawa seseorang anggota polis. Menurut Roberg, Novak, dan Cordner (2019), polis sering diperhatikan oleh khalayak umum seperti masyarakat media sosial dan peguam bela. Tugas polis terdedah kepada mengawal keganasan dan keadaan kawasan (Perrot \& Kelloway, 2006). Menurut Don dan Brett (2011), kerjaya sebagai penguatkuasa undang-undang sering dikelilingi oleh beban. Oleh itu, majikan perlu bertanggungjawab bagi memastikan anggota polis menerima kebajikan dengan sewajarnya dan setimpal dengan tugasan mereka bagi terus menjamin keamanan negara.

Menurut Patterson (2009), masalah yang berlaku dalam kalangan polis sering dikaitkan dengan punca berlakunya tekanan dalam kalangan anggota polis yang disebabkan oleh bebanan kerja dan masalah peribadi seperti masalah kewangan, keluarga, kebajikan dan sebagainya. Hal ini akan menyumbang kepada penurunan prestasi kerja akibat daripada tekanan yang dihadapi oleh anggota polis. Menurut kajian yang dijalankan oleh Wu et al. (2010), pekerjaan sebagai seorang anggota polis akan cenderung kepada tekanan kerja yang tinggi dan juga dipercayai akan memberi kesan kepada kesihatan mental dan fizikal yang disebabkan oleh faktor persekitaran kerja dan faktor peribadi. Oleh itu bagi meringankan tekanan dan beban anggota polis, kebajikan anggota polis perlulah dijaga. Kenyataan ini disokong lagi dengan kebajikan yang dilakukan dengan sebaik mungkin dalam menjaga hubungan terhadap Allah dan sesama manusia. Kebajikan merujuk kepada segala perbuatan baik yang mendatangkan manfaat kepada setiap makhluk seperti yang dituntut oleh syariat dan secara tidak langsung akan memenuhi tuntutan manusia juga. Semangat untuk tolong menolong, bekerjasama dan bantu membantu ditekankan dalam menerapkan nilai kebajikan terhadap organisasi dan masyarakat samada secara dalaman ataupu luaran (Mohamad Khadafi, 2015).

\section{Kebajikan}

Menurut Mohamd Khadafi (2015), antara budaya kebajikan dalam organisasi budaya Islam yang boleh atau sedang dilakukan dalam organisasi di Malaysia ialah memastikan ahli organisasi mempunyai simpanan di hari tua, memperuntukkan insuran kemalangan, rawatan penyakit berat dan kematian, menyediakan kemudahan pinjaman dengan pinjaman potongan gaji berjadual tanpa riba, klinik panel untuk pesakit yang ringan, menyediakan kutipan derma kilat untuk ahli organisasi yang ditimpa musibah, ruangan wakaf dan sedekah secara tetap kepada ahli organisasi yang susah, pemberian hadiah dan penghargaan untuk kejayaan anak-anak ahli dan lain-lain. Kebiasaannya keperluan kebajikan ini perlu dimesyuaratkan dengan ahli organisasi untuk mereka memilih aspek yang menjadi keperluan dan keutamaan para pekerja.

Menurut Siti (2019), Ketua Polis Negara menyatakan penubuhan Suruhan Jaya Bebas Aduan dan Salah Laku Polis (IPCMC) ditubuhkan bagi memberi pembelaan kepada hak dan kebajikan seluruh warga Polis Di Raja Malaysia. Hal ini kerana, setiap anggota PDRM berhak mendapat kebajikan yang setimpal dengan jasa dan pengorbanan dalam menjalankan tugas berbakti kepada negara. Perjuangan 
bagi membela nasib anggota polis amat dititikberatkan oleh Ketua Polis Negara kerana beliau tersentuh dengan keadaan perumahan dan balai polis yang daif berikutan tiada peruntukan untuk membaiki kerosakan yang berlaku. Selain itu, terdapat banyak kerosakan yang berlaku seperti bumbung yang bocor tetapi tidak dibaiki kerana tiada peruntukan dan ianya makin menyukarkan keadaan serta memberi bebanan fikiran kepada anggota yang tinggal di kediaman berkenaan.

Namun begitu, menurut Baker dan Ibrahim (2015) pasukan polis di Malaysia turut menghadapi situasi yang sama di mana masalah psikologi dalam kalangan anggota polis di Malaysia semakin meruncing dan terdapat kes yang melibatkan anggota polis seperti masalah mental, membunuh diri, kes pembunuhan dan kes mencederakan orang awam yang berpunca daripada tekanan kerja. Terdapat 14, 438 kes yang melibatkan anggota dan pegawai PDRM sepanjang tempoh empat tahun iaitu dari tahun 2011 hingga 2015 yang dilaporkan melalui laporan perangkaan tatatertib PDRM. Statistik Jabatan Siasatan Jenayah PDRM (2014) menunjukkan bahawa terdapat tiga kes bunuh diri yang melibatkan anggota polis dan empat lagi kes cubaan membunuh diri telah dilaporkan. Penentuan kerjaya individu bergantung kepada tahap tekanan yang dialami dengan sejauh mana ia dapat difahami, dinilai serta luahan emosi. Justeru itu, menurut Boren (2014) bagi menangani masalah ketidakpuasan kerja yang boleh mengakibatkan tekanan, maka seseorang individu perlu mempunyai kemahiran untuk mengurus emosi. Hal ini demikian kerana, anggota polis berdepan dengan pelbagai dugaan serta terdedah kepada bahaya semasa menjalankan tugas. Anggota polis bertindak balas terhadap pelbagai aktiviti jenayah semasa menjalankan tugas bagi menjaga keselamatan dalam negara.

Walau bagaimanapun, kebolehan, ketekunan, kecekapan, kesetiaan seorang anggota polis sangat diperlukan oleh majikan bagi menjamin keselamatan negara yang telah dipertanggungjawabkan kepada mereka. Namun begitu, anggota polis pula memerlukan keperluan asas seperti kebajikan sebelum mereka memberikan komitmen kepada majikan. Bagi mencapai matlamat majikan, kedua-dua pihak saling memerlukan supaya dapat menghasilkan produktiviti kerja yang memberangsangkan dan dapat menanam sikap kesetiaan dalam diri anggota polis. Oleh itu, organisasi perlu meningkatkan lagi ganjaran dengan menggantikan ganjaran tersebut melalui tawaran kebajikan yang lebih lumayan kepada pekerja. Lantaran itu, faktor-faktor yang mempengaruhi komitmen kerja perlu dikaji bagi menangani masalah kelemahan sesebuah organisasi. Jika punca komitmen dapat dikenal pasti, maka organisasi akan lebih berpotensi untuk meningkatkan komitmen kerja pekerja (Yaacob, 2008).

Menurut laporan dalam Berita Harian yang ditulis oleh Siti (2019) berkenaan kenyataan Ketua Polis Negara, penubuhan Suruhan Jaya Bebas Aduan dan Salah Laku Polis (IPCMC) adalah kerana setiap anggota Polis Diraja Malaysia berhak mendapat kebajikan yang setimpal dengan jasa dan pengorbanan dalam menjalankan tugas berbakti kepada negara. Perjuangan bagi membela nasib anggota polis amat dititikberatkan oleh Ketua Polis Negara. Selain itu, terdapat banyak kerosakan yang berlaku seperti bumbung yang bocor tetapi tidak dibaiki kerana tiada peruntukan dan ianya makin menyukarkan keadaan serta memberi bebanan fikiran kepada anggota yang tinggal di kediaman berkenaan. Menurut Patterson (2009); Ganing dan Hamzah (2020), hal ini dikaitkan dengan punca berlakunya tekanan dalam kalangan anggota polis yang disebabkan oleh bebanan kerja dan masalah peribadi seperti masalah kewangan, keluarga, kebajikan dan sebagainya. Oleh itu, bagi meringankan tekanan dan beban anggota polis, kebajikan anggota polis perlulah dijaga.

\section{Metod Kajian}

Dalam penyelidikan yang dijalankan ini, pengkaji menggunakan kaedah penyelidikan kualitatif. Kaedah penyelidikan yang berbentuk kualitatif adalah sangat penting bagi memperoleh maklumat yang lebih tepat dan mendalam terutamanya maklumat yang melibatkan elemen-elemen lain yang tidak dapat diukur dengan skala nombor dan maklumat yang melibatkan emosi individu tersebut (Othman, 2009). Lokasi penyelidikan adalah di Ibu Pejabat Polis Kontinjen (IPK) Terengganu, Terengganu Darul Iman. Majoriti anggota polis di IPK Terengganu adalah berbangsa Melayu. Jumlah sampel bagi penyelidikan ini adalah seramai 11 orang responden. Menurut Chua (2006), kredibel bagi penyelidikan kualitatif adalah apabila ada orang lain yang bersetuju bahawa mereka mempunyai pengalaman yang sama dialami. Pemilihan sampel pula adalah menggunakan teknik persampelan bertujuan melalui 
pemilihan dari pihak jabatan berdasarkan ciri utama yang ditetapkan oleh pengkaji iaitu berpangkat dari konstabel hingga sarjan.

Kaedah pemerhatian dan kaedah temu bual secara mendalam (in-depth interview) digunakan oleh pengkaji bagi mengumpul data yang diperlukan. Melalui temu bual yang mendalam dengan responden kajian, pengkaji dapat memerhati responden dengan melihat dunia dari kaca mata mereka (Alston \& Bowles, 2003). Temu bual tersebut diadakan di antara pengkaji dengan responden secara individu dan bersemuka dengan topik yang ditentukan oleh pengkaji. Temu bual yang dijalankan menggunakan soalan berstruktur kerana ia dapat memberi fokus kepada objektif kajian yang telah ditetapkan supaya responden dapat memberi jawapan yang tepu untuk kajian. Di samping itu, pengkaji juga menjalankan pemerhatian terhadap bahasa tubuh yang ditunjukkan oleh responden semasa sesi temu bual dijalankan. Hal ini kerana, pengkaji ingin memastikan keselamatan dan keselesaan di antara pengkaji dan responden terjamin. Pengkaji juga mendapatkan data-data sekunder daripada IPK Terengganu seperti maklumat profil yang berkaitan dengan kajian yang dijalankan.

Kemudian apabila selesai semua sesi temu bual yang dijalankan, maklumat berbentuk verbatim yang diperoleh dari sesi temu bual akan dikumpulkan untuk tujuan menganalisis data. Pengkaji akan membaca setiap verbatim sebanyak dua kali supaya pengkaji dapat menghayati dan memahami intipati data dengan lebih terperinci agar dapat memastikan ketepuan maklumat daripada responden kajian. Selepas itu, data tersebut di ekstrak untuk mencungkil tema-tema yang terdapat berdasarkan maklumat yang diperoleh. Komponen atau serpihan idea atau pengalaman akan disatukan bagi mengenal pasti tema yang ada melalui ketiga-tiga komponen tersebut (Ryan \& Bernard, 2003). Seterusnya, data yang diperoleh daripada kaedah analisis tematik ditapis untuk mendapatkan tema tertentu yang telah disebutkan oleh responden. Namun begitu, tema tertentu yang diperoleh dari responden yang lain dianalisis untuk melihat perbezaan antara tema. Selepas itu, untuk mengenal pasti persamaan tema dari setiap kategori data yang diperoleh, pengkaji telah menganalisis data secara melintang dan tema tersebut telah dikelompokkan sebagai tema yang mempunyai persamaan bagi menjawab objektif kajian dan persoalan kajian.

\section{Hasil dan Perbincangan Kajian}

Dapatan menunjukkan terdapat tiga cadangan utama bagi menambahbaikkan aspek kebajikan anggota polis yang berkaitan dengan isu kebajikan. Cadangan penambahbaikan kebajikan yang pertama ialah menambahbaikkan infrastruktur dan keselamatan di perumahan anggota polis. Cadangan kedua pula adalah dengan mengadakan kursus penyeliaan untuk pegawai kanan dan penyelia. Manakala cadangan terakhir pula adalah memudahkan urusan kelulusan permohonan cuti anggota. Majoriti responden kajian menyatakan perasaan tidak berpuas hati dengan tahap kebajikan yang diterima. Responden kajian berkata bahawa mereka masih lagi memerlukan penambahbaikan daripada kebajikan yang sedia ada kerana sering timbul masalah berkaitan isu kebajikan dalam kalangan anggota polis berpangkat rendah. Oleh itu, akibat kurangnya kebajikan yang diperoleh oleh seseorang individu akan mempengaruhi cara individu itu melaksanakan kerja mereka (Hackell dan Violanti, 2003). Oleh hal demikian, cadangan yang dikemukakan oleh responden jelas menunjukkan bahawa masih terdapat kekurangan terhadap kebajikan yang diterima oleh mereka terutamanya dari aspek perumahan.

Banyak jugak rasanya kebajikan yang perlu ditambahbaik, yang pertama sekali perumahan polis hiliran sebab banyak rosak, lif, paip bocor, dari segi kebersihan, keselamatan perumahan. (Responden 4)

Cadangan saya kebajikan yang perlu ditambahbaik tu mesti lebih kepada perumahan. Walaupun tak duk berek perumahan dah. kesian kawan-kawan yang duk berek tu. Jadi mintak naik taraf sikit laaaa struktur perumahan. Bukan apa, kesian anggota yang duk berek. Lif rosak banyak tahun dah. Kesian laaa yang duk tingkat tinggi. Balik kerja penat nak naik tangga lagi. (Responden 5) 
Kalau macam saya duk perumahan tu, saya mintak tolong naik taraf la struktur bangunan perumahan tu. Bukan apa, sebabnya kesian la kita sendiri kena potong elaun perumahan tapi banyak sangat masalah rumah dan memang tak memuaskan. Kita balik kerja penat-penat nak rehat tapi tengok-tengok air mengalir kat dapur. Air tu dari rumah orang atas yang menjijikkan dari tandas rumah orang. Lepas tu paip kat bawah pun selalu bocor terkena motor yang 'parking' kat bawah blok. Jadi perkara ni ganggu ketenteraman saya sebab bau dia busuk sangat sebab yang bocor tu paip dari sisa kumbahan rumah orang ramai. Hm rasa geram sebenarnya, lagi satu, lif lama dah rosak penat lah nak naik tangga tingkat 6 bukan rendah. Balik kerja dah penat lepas tu tambah lagi penat naik tangga. Lepas tu tingkatkan tahap keselamatan kat perumahan ni kadang-kadang yang 'guard' berek tak tutup pun pintu pagar sebabnya bukan apa, saya duduk sorang bujang lagi satu fikir harta benda kereta motor kat bawah bukannya kita sedar kalau jadi apa-apa kat bawah tu sebab pernah berlaku kes kecurian.(Responden 6)

Saya rasa yang perlu diperbaik dari segi bentuk perumahan sebab kesian pada anggota yang tinggal di perumahan lif dah lama rosak kalau tak silap saya dah 3 tahun lebih dan sebelum tu pun kerap sangat rosak. Cuma kali ni memang rosak berpanjangan sampai ke 3 tahun dan dah nak masuk tahun yang ke 4 kalau tak silap saya. (Responden 9)

Tingkatkan keselesaan tempat tinggal iaitu perumahan polis yang disediakan sebabnya bila balik kerja rumah tu tempat nak rehat kalau rumah tak selesa akan rasa serabut sebab banyak sangat kerosakan berlaku (Responden 10)

Oleh itu, bagi menjamin keselamatan dan keselesaan anggota polis, pengkaji berpendapat bahawa pihak PDRM perlu menyediakan insurans kepada anggota polis. Seperti yang sedia maklum anggota polis yang berkhidmat dalam pasukan polis bertugas akan menghadapi pelbagai risiko semasa menjalankan bertugas. Oleh itu, pengkaji mencadangkan supaya perlindungan insurans khas untuk anggota polis dapat dipertimbangkan oleh pihak kerajaan. Dengan tujuan membantu anggota polis menghadapi risiko kemalangan semasa menjalankan tugas serta mendapat imbuhan tertentu sekiranya berisiko menghadapi kecelakaan semasa masih berkhidmat. Dianggarkan seramai 74325 daripada 120 000 anggota polis telah pun menyertai insurans. Namun begitu, inisiatif yang perlu diambil adalah dengan mewajibkan kesemua anggota PDRM menyertai insurans berkelompok yang telah ditetapkan. Hal ini demikian kerana, ianya mampu memberi manfaat kepada setiap warga PDRM yang menyertai insuran tersebut sekiranya berlaku sesuatu bencana yang tidak diingini kepada mereka.

Cadangan ini dikukuhkan lagi dengan hasil kajian yang dijalankan oleh L.Stum (2012), yang menunjukkan bahawa keselamatan nyawa merupakan tingkat keperluan asas yang paling utama. Dalam konteks organisasi, jika keperluan asas seperti keselamatan, nyawa, keturunan, agama dan harta individu tersebut tidak dijaga oleh majikan maka ianya boleh menjejaskan prestasi kerja individu tersebut sekaligus akan menimbulkan ancaman kepada individu. Merujuk kepada konteks kepolisan pula, sudah sedia maklum tugas polis yang sentiasa berhadapan dengan ancaman dan keselamatan nyawa. Oleh itu, keperluan asas seperti keselamatan, keharmonian dalam kehidupan anggota dan keluarga mereka, imbuhan yang lumayan serta peningkatan dalam prestasi kerja perlu diberi keutamaan sebagai jaminan kepada kesejahteraan hidup mereka apabila kesemua keperluan asas dilengkapi dengan sempurna. Hasil dari kajian ini menunjukkan bahawa antara kesan yang dihadapi oleh anggota apabila kebajikan mereka tidak dijaga adalah timbul perasaan negatif seperti rasa tidak dihargai kerana keselamatan mereka dan keluarga tidak terjamin. Sekiranya pihak PDRM mahu memastikan semua anggota bebas daripada perasaan negatif, maka pihak PDRM perlulah mengambil inisiatif dengan meningkatkan tahap jaminan keselamatan warga PDRM. Oleh itu, pada pandangan pengkaji menerusi isu keselamatan ini adalah dengan mencadangkan supaya pihak PDRM bersama Kementerian Dalam Negeri menyediakan inisiatif penyediaan insurans kepada semua warga PDRM yang masih berkhidmat dalam pasukan. Oleh itu, adalah disarankan agar pihak PDRM mampu memainkan peranan dalam membantu penyediaan insurans kepada anggota polis. Seperti yang telah dinyatakan dalam kajian ini bahawa tugas polis adalah sangat berisiko dan boleh mengancam nyawa 
serta jasa anggota polis sangatlah besar bagi menjamin kesejahteraan orang awam. Maka bukanlah sesuatu yang susah dan mustahil bagi pihak PDRM untuk menyediakan insuran kepada anggota polis bagi menjamin keselamatan mereka.

Seterusnya cadangan kedua yang dikemukakan oleh responden ialah menyediakan kursus penyeliaan kepada pegawai kanan dan penyelia. Cadangan tersebut dikemukakan oleh responden kerana terdapat beberapa isu kebajikan yang melibatkan anggota tertekan dengan sikap pegawai atasan yang mengendalikan mereka. Menurut beberapa orang responden, tekanan yang dihadapi sering berpunca daripada golongan penyelia mereka yang tidak menghormati mereka sebagai anggota bawahan dan hal ini menyebabkan mereka berasa tertekan. Terdapat sembilan orang responden menyatakan bahawa mereka merasa tertekan apabila kebajikan mereka tidak dijaga dengan baik. Bukti kajian yang lepas mengukuhkan lagi fakta ini. Kajian yang dijalankan oleh Masilamani et. al., (2013) yang melibatkan polis di Malaysia menunjukkan bahawa anggota polis menghadapi tekanan kerja pada tahap yang tertinggi. Hasil kajian J M Ravalier et. al., (2021), mendapati bahawa kurangnya sokongan dari pegawai atasan adalah berkait dengan penyalahgunaan perkhidmatan. Rata-rata responden menyatakan bahawa mereka tidak berpuas hati dengan cara penyeliaan pegawai atasan mereka.

Kami sebenarnya bukan 'stress' pasal kerja sangat. Tapi 'stress' dengan sikap manusia yang berlagak bagus. Jadi cadangan saya pihak yang berwajib boleh adakan kursus asas penyeliaan untuk pegawai atasan dan penyelia supaya mereka dapat pupuk nilai bertimbang rasa kepada anak buah dan pamerkan rasa hormat menghormati antara satu sama lain. Sebab kat pejabat, penyelia dan rakan sekerja adalah sahabat dan kita memang perlukan sahabat untuk penuhkan nilai kasih sayang macam kat rumah kita ada keluarga. Sama juga kat pejabat sebab kerja ni kan ibadah dah tentu kita nak pupuk nilai yang baik-baik. (Responden 1)

Banyak jugak rasanya, pihak yang berwajib perlu tingkatkan nilai-nilai murni dalam kalangan anggota contohnya buat kursus atau ceramah motivasi. Bukan apa, nilai-nilai murni boleh mempengaruhi tahap kerja kita yang sebenarnya. Kalau kita rasa dihargai dan saling hormat menghormati antara satu sama lain dah tentu akan buat kita rasa tenang nak buat kerja. (Responden 4)

Yang perlu tambahbaik macam yang soalan tadi la kat kebajikan yang diperlukan tu. Pihak yang berkuasa perlu atau wajibkan mana-mana individu diberi kursus yang sepatutnya. Contohnya kursus penyeliaan bagi pegawai atasan atau penyelia berpangkat sarjan dan ke atas supaya mereka lebih memahami cara mengendalikan anggota mereka sebab bagi saya tahap pendidikan mempengaruhi cara orang atasan atau penyelia menyelesaikan masalah sama ada secara professional atau tidak professional. (Responden 7)

Bagi saya yang terbaik untuk ditambahbaik kebajikan anggota polis ialah apabila diberi peluang untuk berkomunikasi membincangkan secara terus dengan pihak atasan. Lepas tu tambahbaik dari segi penerapan budaya yang sepatutnya sebab orang atasan perlu jadi idola supaya tiada rahsia antara pegawai dan anggota yang berada dibawah penyeliaan mereka dan perlu jadi rujukan kepada anggotanya supaya sifat saling hormat menghormati antara satu sama lain terjalin sebab sebelum ni saya tugas balai duduk dengan sorang (OCS) ketua polis balai ni 'stress' gila sebab tak ada adab tak hormat orang, jadi boleh usulkan supaya pegawai dan penyelia menghadiri kursus pengurusan pengendalian orang bawahan. (Responden 8)

Oleh itu, berdasarkan hasil kajian pengkaji berpendapat bahawa stigma dan diskriminasi dari pegawai atasan merupakan salah satu faktor yang menyebabkan kesan yang dihadapi oleh anggota polis. Pegawai atasan memainkan peranan sebagai penyelia dalam melaksanakan strategi operasi. Oleh itu, mereka perlu bertindak sebagai pihak pengantaraan di antara pihak pengurusan PDRM kepada anggota polis dan kakitangan awam PDRM yang lain. Sebagai seorang penyelia kepada anggota polis, pegawai kanan polis perlu memiliki ilmu tentang cara penyeliaan yang sewajarnya kerana ia adalah sangat 
membantu semasa menyelesaikan sesuatu permasalahan ataupun semasa membuat sesuatu keputusan sebelum mengutarakan arahan kepada anggota di bawah penyeliaannya. Menurut Arnetz et al., (2013), perubahan yang ketara akan berlaku terhadap tingkah laku serta tindak balas psikologi dan fisiologi apabila individu gagal mengawal tindak balas. Hal ini demikian kerana, dalam konteks bidang kepolisan yang sering menjalankan tugas dan tanggungjawab hakiki yang berisiko tinggi.

Terdapat pelbagai isu atau konflik yang timbul contohnya salah faham akibat daripada cara penyampaian arahan atau komunikasi, hubungan peribadi dan ketidakpuasan hati. Oleh itu menurut Dewi (2012), hubungan interpersonal perlu wujud dalam tiga keadaan iaitu di antara penyelia, rakan sepasukan dan pekerja di bawah penyeliaan yang merujuk kepada hubungan yang terjalin antara anggota polis sesama anggota polis dalam organisasi polis. Bagi memastikan perlaksanaan tugas menjadi lebih berkesan perlu wujud satu hubungan melalui interaksi secara saluran komunikasi. Jika dilihat di pejabat, hubungan ini merujuk kepada hubungan pegawai kanan polis dengan pegawai pangkat rendah, hubungan dengan rakan sekerja, dan hubungan dengan orang awam. Oleh itu, pihak yang berwajib perlu mengambil tindakan bagi mengurangkan stigma dan diskriminasi pegawai atasan terhadap anggota mereka. Hal ini demikian kerana, menurut Yukl (2010) dan Luthans (2006), sebagai seorang pemimpin yang akan memberi motivasi kepada pekerja, pegawai atasan perlu mempunyai gaya kepimpinan yang baik supaya pekerja bawahan akan melakukan kerja yang lebih baik secara tidak langsung akan meningkatkan keyakinan diri pekerja bawahan dan akan mempengaruhi peningkatan prestasi.

Seterusnya, cadangan ketiga daripada responden, memudahkan kelulusan permohonan cuti anggota polis. Rata-rata responden memberikan jawapan bahawa pegawai atasan sukar memberikan kelulusan cuti kepada mereka. Hal ini demikian kerana, pegawai atasan tiada sikap toleransi kepada anggota bawahan.

Kebajikan yang dapat biasanya cuti la tapi sepatutnya kena tambah cuti kecemasan sebab cuti kecemasan diberi tiga hari je. Kalau boleh tambah lagi baik sebab kadang-kadang boleh tambah atas pegawai atau penyelia yang luluskan tapi sekarang dah tukar pegawai jadi nasib anak buah la dia tak boleh toleransi dan takde timbang rasa kat anak buah yang hadapi masalah ni. Fikir diri sendiri je yang betul. (Responden 1)

Hmm, lagi apa eh, haaa permohonan cuti anggota perlulah lebih bertimbang rasa dari pihak atasan. (Responden 4)

Hm, kalau ikut pengetahuan saya semua kebajikan dalam sektor perkhidmatan awam telah tersedia mengikut keperluan semasa tapi jika diberi peluang untuk mengemukakan cadangan penambahbaikan, saya nak cadangkan supaya penyelia memberikan kelonggaran cuti kecemasan dan memudahkan kelulusan cuti tahunan sebab tu yang kita nampak secara 'official' tapi yang 'unofficial' dia 'in case' keluarga mati sekali pun kalau pegawai cakap tak boleh tetap tak boleh cuti sebab dah ada kes sebelum ni. ya saya 'admit' bila kita dah 'sign' surat jadi penjawat awam tugas dah jadi 'number one' tapi kenapa tak da timbang rasa? Apa yang saya cakap ni tak semua pegawai macam tu ada yang bagus bagi cuti 3 hari kecemasan dan boleh sambung lebih dari 3 hari dan ada juga yang bebal tak boleh lebih dari 3 hari walaupun ada urusan penting. Sebab dalam kes macam ni orang atasan yang pegang kelulusan 'so' kebajikan yang disalurkan atas dia nak bagi ke tak. (Responden 8)

Lepas tu, mudahkan urusan kelulusan cuti dengan timbang rasa pihak yang bertanggungjawab. Banyak kos yang perlu ditanggung. Satu lagi saya minta pihak kebajikan PDRM memberi kelonggaran anggota PDRM menziarahi ahli keluarga yang tinggal jauh. (Responden 9) 
Pada pandangan pengkaji, organisasi polis memerlukan pekerja sosial di organisasi. Hal ini demikian kerana, apabila wujudnya pekerja sosial di organisasi ianya boleh menjadi satu keperluan memandangkan sering berlaku masalah dalam kalangan anggota polis mahupun pegawai kanan polis. Pihak majikan perlu memandang serius isu tersebut kerana polis merupakan pasukan keselamatan negara yang disanjungi. Oleh itu, pekerja sosial di organisasi polis adalah satu keperluan bagi menangani isu masalah yang berlaku dalam kalangan warga PDRM. Pekerja sosial di organisasi bukan sahaja menjalankan tugas untuk menyelesaikan masalah seperti masalah salah laku anggota polis, tetapi pekerja sosial bertanggungjawab untuk meningkatkan kefungsian sosial dalam diri anggota polis itu juga. Dan adalah satu yang membanggakan apabila pekerja sosial di organisasi telah banyak digunakan di pelbagai sektor kerana faedah positif yang diberikan dalam perkhidmatan sosialnya dengan menolong pekerja di organisasi tersebut.

Oleh itu, pengkaji berpendapat bahawa pekerja sosial di organisasi polis adalah satu keperluan kerana kerja sosial di organisasi dapat ditakrifkan sebagai bidang praktik. Tambahan lagi melalui kaedah ini, masalah sosial boleh ditangani dengan menggunakan kaedah intervensi dan mengaplikasikan kaedah bantuan yang bertujuan untuk mengekalkan penyesuaian optimum antara individu dan persekitaran kerja. Oleh hal yang demikian, pekerja sosial memainkan peranan, tugas dan fungsi dalam aspek dalaman dan luaran kepada organisasi (Miller, 2012). Selain itu, pekerja sosial di organisasi berperanan memberikan khidmat intervensi kelompok kepada warga PDRM yang memerlukan seperti terapi secara berkelompok serta latihan dan pembangunan. Wan Anor Wan Sulaiman (2015) berkata bahawa intervensi kelompok adalah satu perkhidmatan yang menyediakan khidmat membantu berbentuk pertolongan dari segi berinteraksi, menjalinkan hubungan, mencegah perkembangan, mengubati dan membina perubahan tingkah laku dalam kehidupan seseorang individu yang dilakukan secara intervensi berkelompok bagi membantu individu dalam menyelesaikan masalah yang sama.

Seterusnya, bentuk perkhidmatan dari pekerja sosial di organisasi itu bukan hanya merangkumi bahagian dalaman organisasi sahaja tapi juga melibatkan bahagian luaran organisasi. Ini kerana kejayaan sesebuah organisasi adalah bergantung kepada pergerakannya. Oleh itu menurut Pradini (2015), peranan pekerja sosial adalah menjamin kefungsian sosial anggota polis dalam organisasi kepolisan. Dalam konteks mencapai matlamat organisasi, seorang pekerja sosial perlu proaktif dalam membudayakan aspek kepimpinan terhadap kliennya. Pelbagai peranan yang boleh dimainkan oleh seseorang pekerja sosial di organisasi. Namun beberapa peranan penting perlu diketahui adalah peranan sebagai pembangun program, perancang kerja sosial dan pembangun organisasi (Brueggemann, 2002). Selain itu, pekerja sosial di organisasi polis juga boleh melibatkan diri dalam menyokong advokasi sosial dan dasar sosial organisasi. Advokasi sosial adalah satu perkhidmatan yang dilakukan oleh pekerja sosial dalam usaha bantuan klien mencapai kefungsian sosialnya serta merancang dasar sosial dan program berkaitan kesejahteraan sosial klien. Pekerja sosial yang mengambil bahagian dalam dasar sosial boleh melakukan hal yang berkaitan perkhidmatan sokongan sosial yang dilaksanakan oleh organisasi dengan melibatkan bidang keselamatan sosial, perumahan, Pendidikan, kesihatan serta perkhidmatan sosial klien.

\section{Kesimpulan}

Secara keseluruhannya, dapatan kajian ini menunjukkan bahawa majoriti anggota polis yang telah menjadi responden kajian terkesan dengan kebajikan yang diterima sepanjang berkhidmat dalam pasukan polis. Isu yang dihadapi oleh mereka patut segera ditangani dengan mengaplikasikan cadangan yang telah dicadangkan supaya mereka dapat menjalankan komitmen tugas mereka dengan lancar. Hal ini kerana, anggota polis merupakan tunjang utama negara dalam menjaga kesejahteraan orang awam dan keselamatan negara. Pelbagai alternatif dapat dilaksanakan oleh pihak pengurusan PDRM seperti program yang sesuai bagi membantu anggota polis untuk menggunakan pendekatan tertentu supaya dapat menangani situasi berkenaan isu kebajikan yang timbul. Oleh itu, diharapkan agar pihak pengurusan tertinggi PDRM dapat mengambil tindakan yang sewajarnya dan memandang serius isu ini. Pengkaji berpandangan bahawa, pendekatan yang terbaik adalah dengan menggunakan khidmat seorang pekerja sosial bagi membantu mana-mana anggota polis yang mengalami masalah berkaitan tugas sebagai seorang anggota polis dan masalah peribadi. Dengan kemahiran dan skill seorang pekerja 
sosial yang profesional, segala masalah yang dialami oleh anggota PDRM dapat ditangani dengan baik dan berkesan serta dapat meningkatkan komitmen kerja anggota PDRM. Akhir kata, pengkaji berharap supaya kajian dalam bidang ini perlu berterusan dengan kaedah yang lebih terperinci dan skop yang lebih luas oleh pengkaji yang akan datang. Hal ini kerana, diharapkan hasil daripada kajian yang diperoleh akan dapat membantu pihak PDRM menambahbaikkan dan mendapat idea untuk melaksanakan program intervensi yang bersesuaian pada masa yang akan datang kepada seluruh warga PDRM:

\section{Rujukan}

Abdullah, D. (2015). Konsep kebajikan ( al-Birr ) dalam al-qur' an:, 4(1), 192-196.

Alston, M., \& Bowles, W. (2003). Research for social work: An introduction to methods (5th edition). London: Routledge.

Arnetz, B. B., Arble E., Backman L., Lynch A., \& Lublin, A. (2013). Assessment of prevention program for work-related stress among urban police officers. International Archives of Occupational and Environmental Health, 86(1), 79-88.

Azman, Z. (2020). Pengawasan Komuniti Dan Pencegahan Jenayah Di Malaysia: Sejarah Perkembangannya. The Malaysian Journal of Social Administration, 14(2), 39-61.

Baker, R. \& Ibrahim, H. I. (2015). Tekanan kerja dalam organisasi kepolisan: Tinjauan dalam perspektif kecerdasan emosi. Jurnal Kemanusiaan, 23,1-24.

Brueggemann, G. W. (2002). The pactice of macro social work (edisi ke-2). Sdyney: Brooks/Cole

Cheong, J. \& Yun. I. (2011). Victimization, stress and use of force among South Korean Police Officers. Policing: An International Journal of Police Strategies and Management, 34(4), 606624.

Chua, Y. P. (2006). Kaedah kajian. Kuala Lumpur: McGraw Hill Education.

Dewi, Sarita, Permata. 2012. Pengaruh Pengendalian Internal Dan Gaya Kepemimpinan Terhadap Kinerja Karyawan SPBU Yogyakarta (Studi Kasus Pada SPBU Anak Cabang Perusahaan RB.Group). Jurnal Nominal/Volume I Nomor 1/Tahun 2012. Fakultas Ekonomi Universitas Negeri Yogyakarta.

Don I. \& Brett G. (2011). Stress and burnout in policing: Does military experience matter?

Hackell, D. P., \& Violanti, J. M. (2003). Police suicide: Tactics for prevention. Springfield: Charles C. Thomas Publisher.

Graham, A. Y. (2012). A survey of job satisfaction of senior staff of The University of Cape Coast. Prime Journal of Social Science, 1(2), 11-28.

Ganing, C. F., Hassan, M. M., \& Hamzah, W. N. N. W. (2020). Faktor-faktor yang Mempengaruhi Tekanan Kerja di kalangan Kakitangan Hospital Kerajaan. Malaysian Journal of Social Sciences and Humanities (MJSSH), 5(10), 151-177.

J M Ravalier, P McFadden, C Boichat, O Clabburn, J Moriarty (2021). Social Worker Well-being: A Large Mixed-Methods Study. The British Journal of Social Work, Volume 51, Issue 1, January 2021, Pages 297-317

Johari Y. (2019, Februauri 12). Kebajikan polis, siapa peduli? Sinar Harian. Diakses dari https://www.sinarharian.com.my/article/12427/KOLUMNIS/Kebajikan-polis

Jusoh, R., \& Mhamat Nasudin, N. N. (2013). Relationship between emotional quotient and the level of job satisfaction among secondary school teachers. International Journal of Science Commerce and Humanities, 1(7), 70-79.

L.Stum, David. 2001. Maslow revisited: building the employee commitment pyramid. Strategy \& Leadership 29(4): 4-9.

Masilamani, R., Bulgiba, A., Chinna, K., Darus, A., Isahak, M., Kandiben, S., \& Koh, D. (2013). Prevalence and associated factors of stress in the Malaysian police force. Science Direct Preventive Medicine, 57, S57-S59.

Metcalfe, B. \& Dick, G. (2002). Is the force still with her? Gender and commitment in the police, Women in Management Review, Vol. 17 No. 8, pp. 392-403.

Miller, L. (2012). Counselling skills for social work (2nd edition). London: SAGE Publication Ltd.

Miller, L. (2006). Practical police psychology: Stress management and crisis intervention for law enforcement. Spring Weld: Charles C. Thomas. 
Mohamad Khadafi, H. R. (2015). Prinsip Etika Kerja Islam Menurut Al-Quran dan ALSunnah: Satu Penilaian Terhadap Karya Penulis Etika Kerja Islam di Malaysia. Tesis Phd, Universiti Utara Malaysia.

Mohd Bokti, N. L., \& Abu Talib, M. (2010). Tekanan kerja, motivasi dan kepuasan kerja Tentera Laut Armada Tentera Laut DiRaja Malaysia. Jurnal Kemanusiaan, 15, 46-62.

Moradi, M., Honari, H., Naghshbandi, S., Jabari, N., \& Azarpira, G. (2012). The relationship between emotional intelligence and job satisfaction among coaches in premier under-20 football league. International Journal of Academic Research in Business and Social Sciences, 2(6), 73-83.

Nhan Dan. (2015). Vietnam, Malaysia sign agreement on transnational crimes. Diakses dari https://en.wikipedia.org/wiki/Royal_Malaysia_Police

Othman, L. (2009). Kajian kualitatif: Pengenalan kepada teori dan metod. Tanjong Malim: Penerbit Universiti Pendidikan Sultan Idris.

Patterson, G. T. (2009). Mental stress and workers' compensation claims among police officers. Journal of Workplace Rights, 14(4), 441-445.

Pradini, D. D., Siti A, D. H., \& Irfan, M. (2015). Peran Pekerja Sosial Dalam Dunia Industri di Indonesia. Prosiding KS: Riset dan PKM, 147- 300.

Roberg R.., Bradley S. (2019), Police \& Society. Eighth Edition

Robert D. Tennyson (2010). A study of student satisfaction in a blended e-learning system environment. Computers \& Education 55(1):155-164

Ryan, G. W., \& Bernard, H. R. (2003). Techniques to identify themes. Field Methods, 15(1), 85-109.

Salmah Binti Othman. (2009). Kecerdasan emosi dan tekanan kerja serta hubungannya dengan komitmen kerja dalam kalangan anggota polis diraja Malaysia. Tesis Sarjana UUM.

Mohamed Sazif Mohamed Subri. 2011. The Stress Effect Towards PDRM Personnel: A Case Study on Health Problems and Job Satisfaction in Kedah. Masters Diss., Universiti Utara Malaysia, Sintok, Kedah.

Slate, R. N., Johnson, W. W., 7 Colbert, S. S. (2007). Police stress: A strucutural model. Journal of Police and crimical psychology, 22, 102-112.

Siti, A. A. (2019, Mei 30). IPCMC: KPN mahu bela hak, kebajikan seluruh warga PDRM. Berita Harian. Diakses dari https://www.bharian.com.my/berita/nasional/2019/05/569935/ipcmc-kpnmahu-bela-hak-kebajikan-seluruh-warga-pdrm

Venugopal Navaretnam. 2011. The influence of leadership styles/behavior and competencies towards the job satisfaction of employees in the royal malaysia police. Master's Diss., Universiti Utara Malaysia, Sintok, Kedah, Malaysia.

Violanti, J. M., Charles, L. E., Gu, J. K., Burchfiel, C. M., Andrew, M. E., Joseph, P. N., \& Dorn J. M. (2013). Associations of depressive symptoms and brachial artery reactivity among police officers. Safety and Health at Work, 4(1), 27-36.

Wan Anor (2018). Kaunseling Kelompok Terapi Kognitif dalam Pengurusan Stres dalam kalangan Polis. Universiti Malaysia Sabah.

Yukl, Gary. 2010. Leadership in Organization. Alih Bahasa oleh Udaya Jusuf: Kepemimpinan dalam Organisasi. Jakarta: Prehallindo.

Yun, I., Kim, S. G., Jung, S. J., \& Shahin, B. (2013). A study on police stressors, coping strategies and somatization symptoms among South Korean Frontline Police Officers. Policing: An International Journal of Police Strategies \& Management. 36(4), 787-802.

Yusoff, E. Y. B. C. (2016). Hubungan Kepuasan Kerja Dengan Kecerdasan Emosi Dalam Kalangan Warga Polis Diraja Malaysia Di Ibu Pejabat Polis Daerah, Selangor, Malaysia.

Yaacob, Z. (2008). Kesan Pengurusan Kualiti Terhadap Prestasi Perkhidmatan Pihak Berkuasa Tempatan (Quality Management Effect Towards Local Authority Service Performance). Jurnal Kemanusiaan, 6(2). 